\title{
O estruturalismo dialético, psicanálise e o nascimento da psicoterapia de grupo
}

\author{
The dialectical structuralism, psychoanalysis and the birth of group psychotherapy \\ El estructuralismo dialéctico, psicoanálisis y el nacimiento de la psicoterapia de grupo
}

\author{
Enidio Ilario* \\ Antonios Terzis**
}

\begin{abstract}
Resumo
O estudo busca mostrar a riqueza da abordagem grupal, que resgata fontes esquecidas e constitutivas da teoria psicanalítica, amalgamadas no constructo freudiano, formando um todo articulado que tende a velar suas fontes primevas. Entre tais fontes, o idealismo alemão, o pragmatismo americano e o estruturalismo, os últimos, nascentes à época de Freud, contemporâneo de Peirce e Saussure. De tal matriz, sobretudo da noção de alteridade como reconhecimento, a influência sobre uma geração de psicanalistas, entre eles aqueles preocupados com a questão da grupalidade e que produziram seus construtos no início do século XX, pertencentes à Escola de Relaçōes Objetais. Conjectura-se, neste estudo, que a inquietação e a insatisfação desses autores com as limitaçôes dos modelos existentes, inclusive a metapsicologia, para explicação ou mesmo a compreensão dos fenômenos da grupalidade, tenham contribuído para lançar as bases para o projeto transdisciplinar da ciência da cognitiva.
\end{abstract}

Palavras-chave: Grupo. Relações objetais. Alteridade. Dialética. Estruturalismo.

\begin{abstract}
The present study aims to show the richness of the group analytic approach, which includes many sources that are forgotten and even constitutive of psychoanalysis. Such sources are amalgamated in the Freudian construct and form an articulated whole, which tends to obscure their importance. Among these sources are German Idealism, American Pragmatism and Structuralism, the last two emerging at the time of Freud, himself a
\end{abstract}

\footnotetext{
Texto recebido em março 2012 e aprovado para publicação em junho de 2015.

Doutor em Psicologia pela Pontifícia Universidade Católica de Campinas (PUC Campinas), mestre em Filosofia pela PUC Campinas, pesquisador do Centro de Lógica, Epistemologia e História da Ciência (CLE-Unicamp), médico e professor colaborador do Centro Interdisciplinar de Bioética da Faculdade de Medicina da Unicamp. Endereço: Rua Mogi Guaçu, 569 Chácara da Barra, Campinas-SP, Brasil. CEP: 13090-605. E-mail: enidioil@fcm.unicamp.br.

"* Doutor em Psicologia pela Universidade de São Paulo (USP), mestre e especialista pela Universidade Paris VII, ex-docente da Pós-Graduação da PUC Campinas, autor e orientador de diversas dissertaçōes e teses de doutorado, professor convidado da Famema e UFSCar, ex-presidente da Flapag, diretor do Cefas. Endereço: Rua Mogi Guaçu, 569 - Chácara da Barra, CampinasSP, Brasil. CEP: 13090-605.E-mail: cursos@cefas.com.br.
} 
contemporary of Peirce and Saussure. From this matrix of ideas, the notion of alterity in the sense of recognition stands out as influencing a generation of psychoanalysts, including those in the early twentieth century concerned with groups and belonging to the so-called school of object-relations theory. It is conjectured in this study that the disquiet and dissatisfaction of these authors with the limitations of existing models (including metapsychology) as a means of explanation or of even understanding of groupality phenomena, has contributed, along with other areas of knowledge such as structuralism and cybernetics, to the development of the contemporary transdisciplinary project of cognitive science.

Keywords: Group. Object-relations. Alterity. Dialectics. Structuralism.

\section{Resumen}

Este estudio tiene como objetivo mostrar la riqueza del enfoque grupal, que rescata muchas fuentes que han sido olvidadas y que son constitutivas de la teoría psicoanalítica, amalgamadas en el constructo freudiano, formando un conjunto articulado, que tiende a velar sus fuentes primeras. Entre tales fuentes, el idealismo alemán, el pragmatismo americano y el estructuralismo, los últimos, nacieron en la época de Freud, contemporáneo de Peirce y Saussure. A partir de esta matriz, sobre todo de la noción de alteridad como reconocimiento, la influencia en una generación de psicoanalistas, incluyendo aquellos preocupados con la cuestión de la grupalidad y que produjeron sus constructos en los inicios del siglo XX, pertenecientes a la Escuela de Relaciones Objetales. Se conjetura en este estudio que la inquietud y la insatisfacción de estos autores con las limitaciones de los modelos existentes (incluyendo la metapsicología) para explicar o incluso comprender los fenómenos de la grupalidad, han contribuido a sentar las bases del proyecto transdisciplinario de la ciencia cognitiva.

Palabras clave: Grupo. Relaciones objetales. Alteridad. Dialéctica. Estructuralismo.

\section{Introdução}

"No mind is an island" (Deacon, 1998, tradução nossa). ${ }^{1}$

0 estudo é um desdobramento de aspectos tratados em tese de doutorado em psicologia do (Ilario, 2011) e busca mostrar a riqueza da abordagem grupal, que resgata fontes esquecidas e constitutivas da teoria psicanalítica, amalgamadas no constructo freudiano, formando um todo articulado que tende a velar suas fontes primevas. Entre tais fontes, o idealismo alemão, o pragmatismo americano e o estruturalismo, os últimos, nascentes à época de

\footnotetext{
1 “Nenhuma mente é uma ilha."
} 
Freud, contemporâneo de Peirce e Saussure. De tal matriz, sobretudo da noção de alteridade como reconhecimento, vai exercer importante influência sobre uma geração de psicanalistas preocupados, sobretudo, com a questão da grupalidade e que produziram seus construtos no início do século $\mathrm{XX}$, pertencentes à Escola de Relações Objetais. Para fundamentar nossas conjecturas, buscaremos traçar um breve itinerário desse rico período para o desenvolvimento da teoria psicanalítica de grupo, enfocando contributos como os de Bion e Foulkes e, mais recentemente, Pichon-Rivière e Kaës. Contemporâneos de Bion e Foulkes, mas oriundos de outras tradiçóes, veremos que psicólogos como Kurt Lewin e Vygotsky, compartilharam das mesmas inquietações e insatisfações com as limitações dos modelos existentes, para explicação ou mesmo a compreensão dos fenômenos da grupalidade, fato que, em nossa opinião, contribuiu para lançar as bases do projeto transdisciplinar da ciência cognitiva.

\section{A metapsicologia e o estruturalismo}

"Pensar afinal é sempre seguir a linha de fuga do voo da bruxa" (Deleuse \& Guattari, 1992).

Foi a partir da introdução dos conceitos de id, ego e superego que a teoria psicanalítica demonstrou mais claramente ser de matiz estruturalista. Tal fato não deve surpreender, dado os indícios anteriores, desde a fase neuroanatômica até a transição para a primeira e segunda tópicas, quando Freud reconheceu as relações estruturais entre as instâncias. Aquilo que o autor denominou de aparelho psíquico nada mais configura que uma estrutura, e isso fica claro no trecho que acompanha o seu clássico diagrama da segunda tópica: "Gostaria de configurar as relações estruturais da personalidade mental, segundo as já descritas para os senhores, neste despretensioso esquema [...]" (Freud, 1933/1987).

Figura 1. Diagrama da segunda tópica freudiana

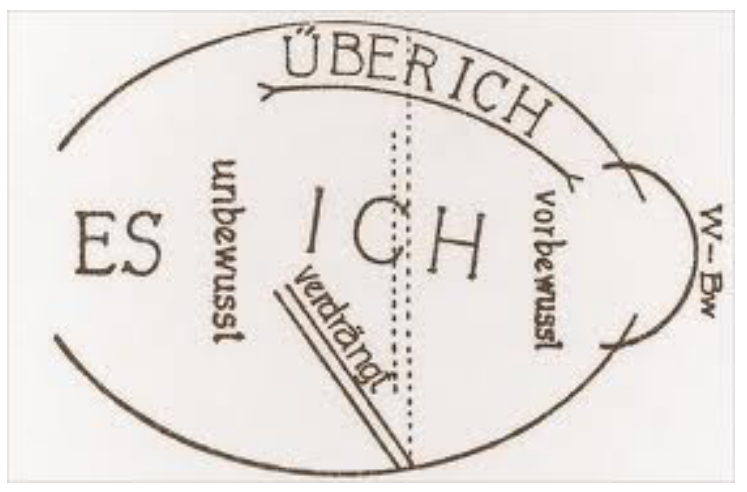

Fonte: Freud (1933). 
Todavia não é fácil ceder às evidências de que Freud, como tantos de seus contemporâneos, foi um rematado estruturalista. Uma questão que poucas vezes se destaca na literatura psicanalítica é que uma abordagem estruturalista não significa reduzir o objeto à dimensão tópica, pois tanto a dimensão dinâmica como a econômica são compatíveis com a abordagem. Talvez uma explicação para que a grande produção em psicanálise, na primeira metade do século XX, pouco atenção tenha dado ao fato é que conceitos básicos da teoria geral dos sistemas, complexidade e auto-organização eram noções ainda não amadurecidas, pois ganharam visibilidade somente a partir da segunda metade do mesmo século. No entanto não deve surpreender a coincidência temporal do modelamento freudiano com os construtos de Saussure e Peirce, autores que contribuíram para dar à Linguística, como parte de uma ciência mais ampla denominada Semiótica, alta reputação no campo científico.

A Semiótica abarca todas as possíveis formas de linguagem, ou seja, tem por objetivo o exame dos modos de constituição de todo e qualquer fenômeno como fenômeno de produção de significação e sentido (Santaella, 1983, p. 14). Nesse campo, o estruturalismo designa algumas correntes da moderna Linguística que se projetaram a partir da obra de Saussure, Curso de Linguistica Geral (1916/1969), ${ }^{2}$ na primeira metade do século XX. Uma estrutura não se compõe apenas de objetos ou elementos, mas também de relações e, no caso da Linguística, de relaçôes entre elementos linguísticos, e a essa noção Saussure denominou valor, dizendo que, mesmo fora da língua, todos os valores parecem regidos por esse princípio paradoxal. Ora, esse princípio paradoxal nada mais é senão aquele que rege as estruturas, chamadas por Saussure de sistemas, às quais corresponde um tratamento que o autor denominou sincrônico em oposição ao diacrônico (histórico).

A concepção sincrônica saussureana certamente contribuiu para que os psicanalistas ignorassem por longo tempo as contribuiçôes do estruturalismo e mais tarde da sistêmica. Aliás, Freud (1910/1987) utilizou o termo "Instanz" como equivalente a "System" e outro momento pertinente à compreensão de uma natureza estrutural do psiquismo, pressuposta em sua obra, encontra-se em "A significação antitética das palavras primitivas", afirmando que "melhor entenderíamos e traduziríamos a língua dos sonhos se soubéssemos mais sobre o desenvolvimento da linguagem". Preocupado em explicar o modo pelo qual os sonhos tratam a categoria de contrários, Freud encontrará a resposta para os seus achados clínicos quando de sua leitura de um panfleto publicado em 1884, no livro Ensaios filológicos (citado por Freud em $A$ significação antitética

2 A primeira data indica o ano de publicação original da obra, e a segunda indica a edição consultada pelo autor, a qual somente será pontuada na primeira citação da obra no texto. Nas seguintes, será registrada apenas a data de publicação original. 
das palavras), do filólogo alemão Carl Abel. O ensaio trata da peculiaridade das línguas antigas e foi escrito em 1880, mesmo ano em que o jovem Saussure defendia sua tese sobre o uso do caso genitivo em sânscrito. Tal coincidência não se resume ao período, mas também à localidade, ou seja, Berlim, cidade na qual vivia e produzia conhecimento Carl Abel, então com 43 anos de idade. Se há poucas evidências da influência dos trabalhos de Saussure em Freud, em compensação, a influência de Carl Abel é confessada, fato que vai tornar o nome do filólogo indissociavelmente ligado ao de Freud.

\section{Alteridade e relações objetais}

"Sem dúvida, a consciência de um Outro, de um objeto em geral, é necessariamente consciência-de-si” (Hegel, 1806/1992).

Sabemos que o pensamento freudiano, embora de reconhecida originalidade, é um fruto de sua época, e por isso inevitavelmente amalgamado com o de tantos outros de seu tempo. Daí é evidente que esse gigante em cujos ombros tantos se alçaram também ganhou alcance de visão sobre o dorso de outros avatares que o precederam. Alguns destes foram identificados e reconhecidos por Freud, outros nem tanto, e não por ingratidão ou desonestidade intelectual, mas, sobretudo, pelo próprio desconhecimento dessas influências, muitas delas indiretas, afinal.

Não há ironia em se afirmar que o culto homem que, sem dúvida alguma, foi Freud, como de hábito ocorre com qualquer pensador, bebeu de muitas fontes no caudal de conhecimento acumulado, sem muitas vezes se dar conta disso. Não há aí qualquer viés na história do conhecimento, e sim a constatação de que prevalece na ciência a lógica construtiva, pois não há construção que se faça sem alicerces ou, em outra metáfora, não há árvore que cresça sem raízes. Por exemplo, da influência do pensamento kantiano sobre a teoria psicanalítica muito já se falou, mas outro grande filósofo alemão, Hegel, influenciou Freud mais do que este ousou reconhecer, não somente pela dialética do senhor e do escravo, mas pelo próprio método dialético.

Mas, se o pai da psicanálise não reconheceu tão marcante influência, ainda que indireta, sobre o seu constructo, muitos de seus discípulos o fizeram, se não no pensamento fundador de Freud, em si mesmos a reconheceram, entre os quais podemos citar Lacan, Bion (1966, 1975), Pichon-Rivière (1986, 2001) e Kaës (1997, 2005). Devemos destacar que, no idealismo alemão, já se encontrava presente, por exemplo, a noção de ego como condição de um "Ser" ativo e livre do conjunto da Natureza, certamente do conhecimento de Freud em sua época. Disso ele nada nos diz. Sobre Hegel, Freud trata somente em duas 
passagens de sua obra, a saber, ao abordar as características distintivas dos sonhos na Conferência XXXV: A questão de uma Weltanschauung (1932/1987), quando demonstra evidentes suspeitas sobre a "obscura filosofia hegeliana, em cuja escola Marx se formou". Sobre a dialética, faz três citaçôes, na Conferência XVI: Psicanálise e Psiquiatria (1917/1987), quando critica a máxima segundo a qual a controvérsia é a mãe de todas as coisas, atribuindo à influência dos sofistas gregos a supervalorização da dialética. Ora, sabemos que a dialética não é sofística, pelo contrário, Platão foi um dialético e, ao mesmo tempo, crítico primoroso dos sofistas. Que não haja entre os grandes idealistas alemães um que desconhecesse a dialética platônica é assertiva que dispensa esforço argumentativo. Para Platão, o Eros traz consigo as duas naturezas do homem, o eu divino e o animal aprisionado, daí nos valermos do fato para lembrar que Freud, mais tarde, tampouco ignorou os insights originários da primeira Academia ( $\mu$ ). No Simpósio de Platão, estão contidos dois tempos importantes para o processo de formação do sujeito: o da socialização, em que na trama coletiva ocorre a sustentação primordial e o momento seguinte da individuação, sendo no transitar constante, nessa via de dois sentidos, uma dialética, que se dá o nascimento da marca humana da subjetividade e da alteridade.

Entre os idealistas alemães, Hegel (1770-1831) destaca-se pela poderosa influência exercida não somente entre seus contemporâneos, mas, sobretudo, no final do século XIX, estendendo-se por todo o século XX. Na Psicologia, o seu pensamento genial e provocador também se fez sentir fortemente, porém de forma mais explícita que na psicanálise, em outros importantes construtos. Da mesma forma como costuma ocorrer com a psicanálise, o pensamento hegeliano encontra-se disseminado por muitos campos e não é por acaso que frequentemente os dois construtos se interpenetram no pensamento contemporâneo, não somente na área da psicologia, mas também no campo da política, da filosofia, da antropologia e da crítica social.

Por exemplo, entre os formuladores da Escola de Frankfurt (teoria crítica), Honneth (2008) e Habermas (1987) vão recorrer a um contemporâneo de Freud, pertencente ao pragmatismo americano, o psicólogo G. H. Mead, que, com o jovem Hegel, compartilha a ideia de que a formação da identidade pessoal passa pelas experiências de reconhecimento recíproco (Souza, 2006). Hegel propõe uma teoria do desenvolvimento do indivíduo fundada no reconhecimento (Anerkennung), um processo conflituoso que pressupõe relações de dependência na busca da afirmação da subjetividade, em uma dialética entre a identidade pessoal e a coletiva. Tal dialética estará presente em toda a sua obra da maturidade e pressupõe a consciência individual como consciência de si, imersa no fluxo vital, movida por pulsões jamais completamente saciadas e, dessa forma, impelida 
para um movimento sem fim. Em tal dialética, o "mal infinito", como Hegel denominou a luta pela dominação e exploração da natureza, deve ir ao encontro de outra consciência de si para obter exatamente o reconhecimento. Nas palavras de Vaz (1991, vol. 2, p. 55-60), a alteridade para Hegel "implica o paradoxo da reciprocidade, segundo o qual o sujeito é ele mesmo no seu ser-conhecido e no conhecer seu outro".

O pensamento dialético hegeliano, sobretudo a noção de alteridade como reconhecimento, vai influenciar toda uma geração de psicanalistas, entre eles, além de Lacan, sobretudo aqueles preocupados com a questão da grupalidade e que produziram seus construtos no final da primeira metade do século XX, pertencentes à chamada Escola de Relações Objetais. Em Melanie Klein, por exemplo, essa influência encontra-se denotada na dialética interior-exterior, quando trata da "posição depressiva" e propõe a saúde psíquica como uma integração bem-sucedida de forças antagônicas no psiquismo (Cintra \& Figueiredo, 2004). A psicanalista inglesa renovou a noção freudiana de pulsão ao afirmar as polaridades que regem a vida psíquica como investir ou não investir o mundo e as pessoas, ou seja, nos domínios do corpo e da linguagem, um território pautado na dialética natureza e cultura (Klein, Heimann, Isaacs \& Riviere, 1986, p. 217). Klein, por meio de sua abordagem da simbolização, seus desdobramentos clínicos e a identificação projetiva, vai influenciar, além de Winnicott, outros grandes psicanalistas.

\section{O nascimento da psicologia de grupo}

“A psicologia de grupo [...] abrange imenso número de temas independentes e oferece aos investigadores incontáveis problemas que até o momento nem mesmo foram corretamente distinguidos uns dos outros" (Freud, 1921/1987)

Na mesma época em que Kurt Lewin desenvolve o seu método e Lacan produzia suas interpretaçôes linguístico-estruturalistas, Bion, médico, psicanalista e, tal como Winnicott, analisando de Klein, vai introduzir uma abordagem inovadora em psicanálise, porém na área de grupo. Embora não considerado de "linhagem estruturalista”, Bion (1966) propõe uma abordagem lógica em Psicologia que procura conectar a uma teoria do pensar que, em sua opinião, tem a Matemática como ideal. Aliás, em Os elementos da psicanálise (p. 12), logo na introdução, o autor confessa que a Matemática e a exatidão de sua execução expressam funçōes da personalidade cujos fatores desejaria conhecer. Tal preocupação em Bion está atrelada à busca de modelos adequados para representar os processos complexos da consciência, da personalidade e da memória. Embora reconheça a imperfeição dessa forma de abordagem, vai dizer que "a imperfeição do modelo 
como instrumento aumenta a força da necessidade de produzir abstrações" (Bion, 1966, p. 82-83). Poincaré (como citado em Bion, 1966, p. 90) acerca da criação da fórmula matemática, diz que "são dignos de nossa atenção somente os fatos que introduzem ordem na complexidade, tornando-a, assim, acessível a nós". Aquele que cunhou a conhecida assertiva: "A mente é um fardo muito pesado, que a besta dos sentidos não aguenta carregar" (Bion, 1975/1990, p. 46), não pôde concluir o seu projeto, que buscou integrar Freud (data?) e Melanie Klein em uma metateoria da mente.

\section{Foulkes e a matriz grupanalítica}

Embora, em sentido estrito, não incluído entre os membros da Escola de Relações Objetais, aquele que cunhou o termo grupanálise, Foulkes (1957/1984), é considerado o criador da psicoterapia psicanalítica de grupo. Segundo Ferreira (1990, p. 11), é com Foulkes que "a grupanálise se transforma claramente num método terapêutico e de investigação ligado aos pequenos grupos". Contemporâneo de Bion, embora de origem alemã, se estabelece na Inglaterra e, com a ajuda de Ernst Jones, ingressa na Sociedade Britânica de Psicanálise à mesma época em que Melanie Klein nela exerce poderosa influência. Daí não é despropositado acreditar que Foulkes deva ser incluso entre os que, com base no referencial teórico da Escola de Relações Objetais, avançam com novos aportes, entre os quais interessa destacar a noção de matriz grupal.

Acerca de tal noção, nos diz Ferreira (1992, p. 45-46) que, em 1951, o psiquiatra americano Jürgen Ruesh e o antropólogo inglês Gregory Bateson publicaram uma obra intitulada Comunicação: a matriz social da psiquiatria, na qual, pela primeira vez, o conceito de comunicação era estudado nas suas várias vertentes e proposto como uma concepção básica em psiquiatria. Foulkes retoma tais noções na obra publicada com E. J. Anthony: Group Psychotherapy: the Psychoanalytic Approach (1957), propondo a grupanálise, em termos de estrutura, processo e conteúdo, para levar a cabo uma ação terapêutica e psiquiátrica (Ferreira, 1992, p. 42). O autor concebeu a noção de matriz grupanalítica com base na teoria psicanalítica e da teoria da Gestalt, de forma que as interações matriciais se expressam em termos de relacionamentos e de fenômeno de espelho (Ferreira, 1992, p. 52). Em tal concepção, é clara a alusão direta ao fenômeno da empatia, do alemão Einfühlung, fenômeno estudado mais tarde na neurociência, os neurônios espelho mirror-neuron. ${ }^{3}$ Para Foulkes, o indivíduo é uma espécie de ponto nodal em uma rede de relacionamentos, a "matriz grupanalítica", noção próxima à de redes de comunicação social, de nítida concepção estruturalista e sistêmica (Ferreira, 1992).

3 Os chamados neurônios-espelho foram descobertos no córtex frontal e parietal do macaco pelo neurofisiologista Giacomo Rizzolatti, Gallese e seus colaboradores da Universidade de Parma (Gallese, 2009). 


\section{Teoria de campo vital de Kurt Lewin: um caso à parte}

Kurt Lewin, outro importante nome no desenvolvimento da psicoterapia de grupo, tal como Bion e, mais tarde, Pichon-Rivière e Kaës, busca na Matemática insights para a construção de sua teoria de campo vital. Muito embora usualmente não incluído entre os gestaltistas integrantes da escola de Berlin, esse versátil psicólogo, com formação em áreas como a Química, a Física e a Filosofia, foi fortemente influenciado por esse grupo. Mas, para além da Gestalt, Lewin tem também uma perspectiva fenomenológica na concepção do espaço vital. Para ele, a função da abordagem fenomenológica "não é a de teorizar, mas a de permitir a elaboração de conceitos que expressem adequadamente o fenômeno que se pretende estudar" (Garcia-Roza, 1974, p. 48).

Para a análise de grupos, o autor aplica os conceitos estruturalistas da Psicologia, concebendo a noção de campo social como o grupo e o seu meio ambiente e, para tal, procede a uma análise topológica puramente qualitativa daquilo que denomina "campo total", em termos de vizinhança, separação, envolvimento, interseçôes, fronteiras, incluindo barreiras e interdições (Lewin, 1049/1973, p. 31-46). No modelo lewiniano o psiquismo humano é movido por forças (vetores) com cargas (valências) positivas ou negativas, e a percepção de um objeto ou fenômeno gera uma tensão que pode assumir o controle da conduta motora. Embora mais tarde demonstre a relevância de uma analítica vetorial, um método calcado na noção das forças psicológicas como entidades vetoriais para o espaço topológico, não tem sucesso na empreitada. A incompletude do projeto lewiniano é usualmente atribuída à sua morte relativamente precoce, mas não se pode desconsiderar a sua confessada dificuldade em conceber a possibilidade de operar vetores no espaço de vida. Dessa forma, Lewin considera discutível a noção de resultante de forças na Psicologia e duvida da possibilidade de transpor a regra do paralelogramo da Física para a Psicologia e da determinação de ângulos, no espaço de vida, a não ser em circunstâncias especiais (Garcia-Roza, 1974, p. 114). É o mesmo autor, contudo, que vai afirmar que não podemos prescindir do conceito de vetor, pois é impossível no caso de uma locomoção psicológica, que apenas uma força exista atuando num momento dado (Garcia-Roza, 1974).

Como se vê, é o próprio autor que nota a necessidade de um modelo que permita a coordenação de forças psicológicas com fatos observáveis para lhe dar validez científica e reconhece a impossibilidade de executar tal operação por meio do modelo disponível, deixando para posteriores pesquisas a determinação $\mathrm{da}$ força simples e das leis relativas às resultantes.

Apesar do fracasso, devemos lembrar o pioneirismo de Lewin ao propor uma analítica vetorial, embora, no campo da psicanálise, tenha sido Franz Alexander 
(1965) o primeiro a aludir a tal possibilidade, embora de forma superficial e sem maiores consequências. Aliás, embora Lewin não seja um psicanalista, reconhece como brilhante o trabalho de Freud na abordagem de problemas profundos, fazendo, contudo, ressalvas acerca das limitações formais e metodológicas, considerando equivocada a tentativa dos psicanalistas de basear inteiramente as leis gerais em estudos anamnésicos e trabalho terapêutico (Lewin, 1949/1973, p. 19).

Interessante destacar que o autor, um rematado estruturalista, poupa de sua crítica justamente a metapsicologia, que considerava brilhante, afinal, tal qual o pai da psicanálise, admite explicitamente a noção de energia psíquica e busca explicar o dinamismo da personalidade inspirado no modelo da termodinâmica. Em sua opinião, na Psicologia, não é necessário discutir a origem dessa energia para que se possa dar um tratamento conceitual no terreno da dinâmica psicológica (Lewin, 1949, p. 20-21).

\section{A teoria do vínculo}

Outro constructo em Psicologia grupal que reflete uma produção pouco mais recente e até hoje pregnante é o de Pichon-Rivière, psiquiatra e psicanalista argentino, criador da "teoria do vínculo" e dos "grupos operativos". Com confessada influências do psicodrama de Moreno, da teoria do campo vital de Kurt Lewin, Freud, Klein, Bion e de outras áreas além da Psicologia (PichonRivière, 1986, p. 9-20), busca integrá-las à sua experiência em um hospital psiquiátrico. Nessa instituição, Pichon-Revière pode observar que os sintomas de seus pacientes podem ser interpretados como códigos, ou seja, o sentido dos delírios e sintomas psicóticos se encontra na estrutura familiar, consequentemente transcendendo o discurso individual.

Para o pai da teoria do vínculo, os conceitos teóricos atuam como instrumental para apreender a realidade e intervir sobre ela, antecipando assim o que o estruturalista francês Michel Foucault mais tarde desenvolverá como sua teoria da caixa de ferramentas 4 . Em sua obra Da psicanálise à Psicologia social (2001), Pichon-Rivière articulou esses conceitos a uma compreensão dialética no seu esquema conceitual referencial e operativo (ECRO), reinterpretando o conceito psicanalítico de inconsciente e desejo à luz do marxismo, como necessidade de transformação com base numa prática social. Com as ciências sociais PichonRivière compartilha a concepção de um sujeito pensado em relação à estrutura social e cultural, mostrando grande afinidade com expoentes da Escola de Frankfurt, as concepções de George Mead e com a dinâmica grupal de Kurt Lewin.

4 Aqui nos referimos a movimento da antipsiquiatria, para quem Foucault ofereceu sua teorização como uma "caixa de ferramentas", conforme entrevista ao Le Monde (citado por Éribon, 1990, p. 158). 


\section{A Escola Francesa}

Mais recentemente, um grupo também marcadamente influenciado pelo pensamento dialético tanto de matiz hegeliano como marxista atua voltado para a psicanálise de grupo e institucional. Entre eles, podemos citar Georges Lapassade, Bleger, Enriquez, Fornari, Fustirer, Roussillon, Vidal e René Kaës. Este último psicanalista, um dos mais importantes da Escola Francesa, embora reconhecendo o valor das contribuições de Pichon-Revière $(1986,2001)$ na questão da grupalidade, vai buscar marcar diferença, ao dizer que Pichon-Revière teria deixado em segundo plano o processo do sujeito no grupo (Kaës, 2005, p. 36-40). O psicólogo francês, nesse caso, critica o que seria a noção pichoniana de que, no sujeito, produzido em uma práxis, nada mais existiria além do que resulta da interação entre indivíduo, grupos e classes. Acerca disso Kaës vai dizer que o sujeito do grupo não é mecanicamente determinado e somente se constitui psiquicamente como sujeito do grupo se puder ser beneficiário desse grupo e, nele, também protagonista (Kaës, 2005).

Dando continuidade ao trabalho do colega e amigo Didie Anzieu, o autor traz importantes contribuições para a psicanálise de grupo, atualmente publicando interessantes textos de matiz dialético, tratando, por exemplo, do trabalho do negativo e da problemática do intermediário como função de mediação nos conflitos grupais (Kaës, 2005, p. 14-15). Com base em noções como "tópica intersubjetiva" e "estrutura do aparelho psíquico grupal", Kaës (1997) busca descrevê-las por meio de três referências teóricas. A primeira é a teoria da forma, afirmando que a estrutura é de nível lógico grupal da psique, direcionada à vida de grupo, sendo os seus elementos, as psiques dos sujeitos singulares associados num conjunto, por exemplo, um grupo (Kaës, 1997, p. 206). O segundo referencial é emprestado da teoria matemática dos grupos: "O princípio de base é que um grupo é um conjunto munido de uma lei de composição interna” (Kaës, 1997, p. 206). Finalmente, o terceiro tem como referência a teoria dos organizadores: "Supus organizadores estruturais, geradores de roteiros e organizadores representacionais (fantasias, mitos, ideologias, utopias)". O autor esclarece que essas três referências funcionam para superar as limitaçōes da metapsicologia do aparelho psíquico individual em direção a uma metapsicologia grupal (Kaës, 1997, p. 207). Destaque-se na obra Kaës, além das referências psicanalíticas, forte presença de contribuiçôes de Kurt Lewin, mesmo que problematizadas, quando, por exemplo, aborda criticamente a dinâmica de grupo (Kaës, 1997, p. 72-73). 


\section{O projeto para uma psicologia científica}

"Uma ciência da cognição poderia ser uma ciência da natureza humana” (Fetzer, 2000).

Se os primeiros construtos na área de psicanálise de grupo podem, a olhos menos avisados, denotar falta de referenciais epistemológicos precisos, em nossa opinião, longe de ecletismo inconsistente, tal peculiaridade demonstra uma saudável busca de integração e estruturação dos vários saberes dispersos desde o nascimento do projeto de uma Psicologia científica. Dentro dessa perspectiva, é visível a tendência de revisitar a obra de Vygotsky, verdadeiro polímata, autor da teoria histórico-cultural dos fenômenos psicológicos. Atento aos aportes dos gestaltistas, compartilha com Kurt Lewin a concepção estrutural de desenvolvimento, Vygotsky $(1998,1999)$ considera, no entanto, a concepção lewiniana por demais biologicista, fisicalista e acrítica, daí o seu progressivo distanciamento.

Autor profícuo e visionário, utiliza conceitos fundamentais da semiótica, antecipando muitas descobertas da neurociência. Vygotsky traça uma visão panorâmica da Psicologia até a sua época, observando a coexistência de três vias utilizadas para o estudo da mente: "A primeira, aquela que renúncia ao estudo da psique, a reflexologia; a segunda, aquela que se propõe a estudá-la através do psíquico, a psicologia descritiva e a terceira, através do inconsciente, a Psicanálise" (Vygotsky, 1999, p. 144-146). Propõe, em vez disso, uma Psicologia dialética, que parte da unidade dos processos psíquicos e fisiológicos (Vygotsky, 1999, p. 193).

Dessa forma, considerava no conjunto de características essenciais da consciência humana a expressão da lei segundo a qual os saltos dialéticos não são apenas transições da matéria inanimada à sensação, mas também desta para o pensamento. Vale destacar que Vygotsky tenta criar uma ciência geral que integre as contribuiçõos de diversas disciplinas particulares de forma original e capaz de tornar possível a pesquisa científica na área. Acredita no iminente surgimento dessa disciplina geral: "A psicologia está grávida de uma disciplina geral, mas ainda não deu à luz" (Vygotsky, 1999, 211-212), dessa forma, antecipou o atual projeto transdisciplinar da ciência cognitiva.

Embora o psicólogo russo seja muito mais citado em textos de filiação cognitivista em comparação com aqueles de base psicanalítica, a psicanálise mesma, não tem se isolado completamente do movimento mais amplo das ciências da cognição. É inequívoca a tendência dentro da própria psicanálise de buscar uma alternativa ao seu crescente isolamento no panorama científico. 
Nesse sentido, o Premio Nobel em Fisiologia e Medicina de 2000, Eric Kandel, afirma acreditar em um renascimento do pensamento psicanalítico a partir da Biologia e, em seu livro Em busca da memória: o nascimento de uma nova ciência da mente (2009), o autor cita, mais do que qualquer outro, Sigmund Freud. O neurocientista afirma que as tendências da psicanálise na busca da superação de seu isolamento científico têm se dado por duas principais vertentes, sendo a primeira delas a da psicoterapia baseada em evidências e a segunda a busca de um alinhamento com a biologia da mente (Kandel, 2009). Importantes achados da neurociência, tais como os "neurônios espelho", correlatos dos processos empáticos, apontam para a pertinência desse alinhamento que, como vimos, mostra-se bastante visível em modelos de psicanálise e psicoterapia de grupo que vem sendo desenvolvidos mais recentemente.

\section{Considerações finais}

Quando uma ciência está a nascer, se é sem dúvida obrigada, para construí-la, a tomar como referências os únicos modelos existentes, quer dizer, as ciências já formadas. Há nelas um tesouro de experiências já feitas que seria insensato não aproveitar (Durkheim, 1895/2002).

Se como afirma o filósofo Ferrater Mora (2004, p. 2410), "Não se pode estudar a história da ética, da teologia, da lógica, etc., sem estudar paralelamente a história do que veio a chamar-se psicologia”, dizemos que tampouco o contrário é possível. Por exemplo, dentro da Psicologia e da Filosofia, o termo cognição está intimamente relacionado com conceitos abstratos, tais como raciocínio, percepção, inteligência, aprendizagem e muitos outros, sendo a cognição considerada uma propriedade abstrata do cérebro ou da mente. Daí a naturalidade do campo transdisciplinar da Ciência Cognitiva que, além da Psicologia e da Filosofia, inclui áreas de estudo como a Inteligência Artificial, a Antropologia, a Neurociência e a Linguística. A Psicologia mantém com todas elas um forte vínculo, partilhando tal condição, quiçá, apenas com a Linguística. Contudo a Psicologia mesma ainda não se constitui como uma ciência canônica, pois nela, sobretudo, o que tem prevalecido é uma acirrada disputa entre várias escolas e seus respectivos modelos. Tal fato acaba, muitas vezes, acarretando grande desperdício de energia, que muito bem poderia ser evitado se, tal como na Física, por exemplo, se compreendesse que um modelo, por menos intuitivo que seja, é sempre um esboço conceitual de algum objeto que se pressupóe estar fora dali. 
Acerca desse ponto, o epistemólogo Mário Bunge (2008), quando trata de modelos em Sociologia, observa que até poucas décadas os processos sociais eram, em geral, considerados inexpressáveis em termos matemáticos. Em sua opinião, tal atitude trai um entendimento deficiente quer da Matemática, quer da Sociologia, por pressupor que a Matemática, quando utilizada, aplicase aos objetos ou referentes do discurso e pressupóe que o método da ciência consiste no conjunto de técnicas empregadas nas ciências físicas. Diz ainda que a infame dicotomia entre as Naturwissenschaften (Ciências da Natureza) e as Geistewissenschaften (Ciências do Espírito) é reforçada por uma filosofia errônea da matemática e da ciência (Bunge, 2008, p. 41-42):

Aprendemos que a matemática pura é neutra e, quando aplicada, é aplicada às nossas ideias sobre juízos acerca de fatos e não sobre os próprios fatos: o que é matematizado não é um naco de realidade, mas algumas de nossas ideias a seu respeito. Esta mudança na filosofia da matemática teve um impacto revolucionário sobre a metodologia da ciência e, ultimamente, sobre a própria ciência. Na verdade, abriu a possibilidade de abordar fenômenos não-físicos com os mesmos instrumentos conceituais (lógicos e matemáticos) e o mesmo método geral (o método científico) que obteve tanto êxito nas ciências físicas.

É irrefutável a evidência de que Freud já intuíra tal fato, pois sempre acreditou na confirmação empírica de suas especulações metapsicológicas: "Ainda que os conceitos e princípios básicos da nova ciência (instinto, energia nervosa, etc.) permaneçam por tempo considerável não menos indeterminado que os das ciências mais antigas (força, massa, atração, etc.)” (Freud, 1940/1987). Ora, como vimos, na Psicologia, poucos como aqueles que buscaram produzir conhecimento no campo da grupalidade modelaram de forma tão desassombrada em relação à matemática e ao método científico. Entre tais psicólogos, aqueles psicanalistas que não aceitaram a interdição freudiana ao caminho que ele mesmo trilhara, ao modelar o psiquismo humano o mais próximo possível da Física, a mais bem constituída das ciências de seu tempo; em tais modelos, sempre presentes explicita ou implicitamente, as noçõos de estrutura e de dialética. 


\section{Referências}

Alexander, F. (1965). Fundamentos da psicanálise. D. Waltensir (Trad.). Rio de Janeiro: Zahar.

Bion, W. R. (1966). Os elementos da psicanálise. Rio de Janeiro: Zahar.

Bion, W. R. (1975). Uma memória do futuro: o sonho. (Vol. 1). São Paulo: Martins Fontes, 1990. (Publicado originalmente em 1975)

Bunge, M. (2008) Teoria e realidade. G. K. Guisburg (Trad.). São Paulo: Perspectiva.

Cintra, E. U. \& Figueiredo, L. C. (2004). Melanie Klein: estilo e pensamento. São Paulo: Escuta.

Deacon, W. T. (1998). The symbolic species: the co-evolution of language and the brain. New York: W. W. Norton \& Company.

Deleuse, G. \& Guattari, F. (1992). O que é a filosofia?. Rio de Janeiro: Ed. 34. (Coleção Trans).

Durkheim, É. (1895). As regras do método sociológico. P. Nassetti (Trad.). São Paulo: Martin Claret, 2002. (Original publicado em 1895)

Eribon, D. (1990). Michel Foucault, 1926-1984. H. Feist (Trad.). São Paulo: Cia. das Letras.

Ferreira, A. G. (1990). Terapia de grupo e grupanálise: sua evolução e perspectiva de futuro em Portugal e no contexto internacional. Revista Grupanálise, 2, 4556.

Ferreira, A. G. (1992). Matriz grupanalítica. Revista Grupanálise, 3, 45-56.

Freud, S. (1910). A significação antitética das palavras primitivas. Conferências introdutórias sobre psicanálise. In J. Salomão (Trad.). Obras completas. (Vol. 11). Rio de Janeiro: Imago, 1987. (Publicado originalmente em 1910).

Freud, S. (1917). Conferência XVI: psicanálise e psiquiatria. Conferências introdutórias sobre psicanálise. In J. Salomão (Trad.). Obras completas. (Vol. 16). Rio de Janeiro: Imago, 1987. (Publicado originalmente em 1917).

Freud, S. (1921). Texto escolhido: psicologia de grupo e a análise do Ego. In J. Salomão (Trad.). Obras completas. (Vol. 18). Rio de Janeiro: Imago, 1987. (Publicado originalmente em 1921). 
Freud, S. (1932). Conferência XXXV: a questão de uma Weltanschauung. In J. Salomão (Trad.). Obras completas. (Vol. 22). Rio de Janeiro: Imago, 1987. (Publicado originalmente em 1932).

Freud, S. (1933). Conferência XXXI: a dissecção da personalidade psíquica. In J. Salomão (Trad.). Obras completas. (Vol. 22). Rio de Janeiro: Imago, 1987. (Publicado originalmente em 1933).

Freud, S. (1940). Texto escolhido: esboço de psicanálise. In J. Salomão (Trad.). Obras completas. (Vol. 23). Rio de Janeiro: Imago, 1987. (Publicado originalmente em 1940).

Foulkes, S. H. \& Anthony, E. J. (1957). Group Psychotherapy. The Psychoanalytic Approach. London: Karnac, 1984. (Publicado com revisões em 1973).

Ftzer, J. H. (2000). Filosofia e ciências cognitiva. Bauru: Edusc. (Coleção Ciências Sociais).

Gallese, V. (2009). Mirror neurons, embodied simulation, and the neural basis of social identification. Psychoanalytic Dialogues, 19, 519-536.

Garcia-Roza, L. A. (1974). Psicologia estrutural em Kurt Lewin. (2a ed.). Petrópolis: Vozes.

Habermas, J. (1987). The theory of communicative action: lifeworld and system - a critique of functionalist reason. Boston: Beacon Press.

Hegel, G. W. F. (1806). Fenomenologia do espírito. Petrópolis: Vozes, 1992. (Original publicado em 1806).

Honneth, Axel. (2008) Trabalho e reconhecimento: tentativa de uma redefinição. Civitas, 8(1), 46-67.

Ilario, E. (2011). Entre individuo-sociedade e natureza-cultura: a constituição do ser-uma modelagem para a psicologia. (Tese de Doutorado). Centro de Ciências da Vida, Pós-graduação em Psicologia, Pontifícia Universidade Católica de Campinas, Campinas.

Kaës, R. (1997). O grupo e o sujeito do grupo: elementos para uma teoria analítica de grupo. São Paulo: Casa do Psicólogo.

Kaës, R. (2005). Os espaços comuns e partilhados: transmissão e negatividade. São Paulo: Casa do Psicólogo. 
Kandel, E. C. (2009). Em busca da memória: o nascimento de uma nova ciência da mente. R. Rubino (Trad.). São Paulo: Companhia das Letras.

Klein, M., Heimann, P., Isaacs, S. \& Riviere, J. (1986). Os progressos da psicanálise. (3a ed.). Rio de Janeiro: Guanabara.

Lewin, K. (1949). Princípios de psicologia topológica. São Paulo: Cultrix, 1973. (Original publicado em 1949).

Mora, J. F. (2004). Dicionário de Filosofia. M. S. Gonçalves, U. S. A. Sobral, M. Bagno, N. N.Campanário (Trad.). São Paulo: Loyola.

Pichon-Rivière, E. (1986). Teoria do vínculo. (2a ed.). São Paulo: Martins Fontes.

Pichon-Rivière, E. (2001). El proceso grupal. Buenos Aires: Nueva Visión. (Del psicoanálisis a la Psicología social, 1)

Santaella, L. (1983). O que é semiótica. São Paulo: Brasiliense.

Saussure, F. (1916). Curso de linguística geral. São Paulo: Cultrix, 1969. (Original publicado em 1916)

Souza, R. F. (2006). George Herbert Mead: contribuiçôes para a Psicologia social. (Dissertação de Mestrado). Programa de Estudos Pós-Graduados em Psicologia Social, Pontifícia Universidade Católica de São Paulo.

Vaz, H. C. L. (1991). Antropologia filosófica I e II (4a ed.). São Paulo: Loyola.

Vygotsky, L. S. (1998). A formação social da mente: o desenvolvimento dos processos psicológicos superiores. M. Cole et al. (Org.), J. Cipolla Neto, L. Silveira M. S. C. A. Barreto (Trad.). (6a ed.). São Paulo: Martins Fontes.

Vygotsky, L. S. (1999). Teoria e método em psicologia. (2a ed.). São Paulo: Martins Fontes. 